\title{
Carotid Artery Infusion via Implantable Jet Port Allround Catheters for Squamous Cell Carcinoma of the Tonsils
}

\author{
Karl R. Aigner, Kornelia Aigner \\ Medias Klinikum, Abteilung für Onokologische Chirurgie, Krankenhausstraße 3a, 84489 Burghausen \\ info@medias-klinikum.de, medias-klinikum.de
}

\section{Introduction}

Radiochemotherapy has a dominant role in the therapy of head and neck cancers. In order to avoid exceeding toxicity from systemic chemotherapy drugs can be administered via the arterial route through special Jet Port Allround Catheters (PFM Cologne).

\section{Material and Methods}

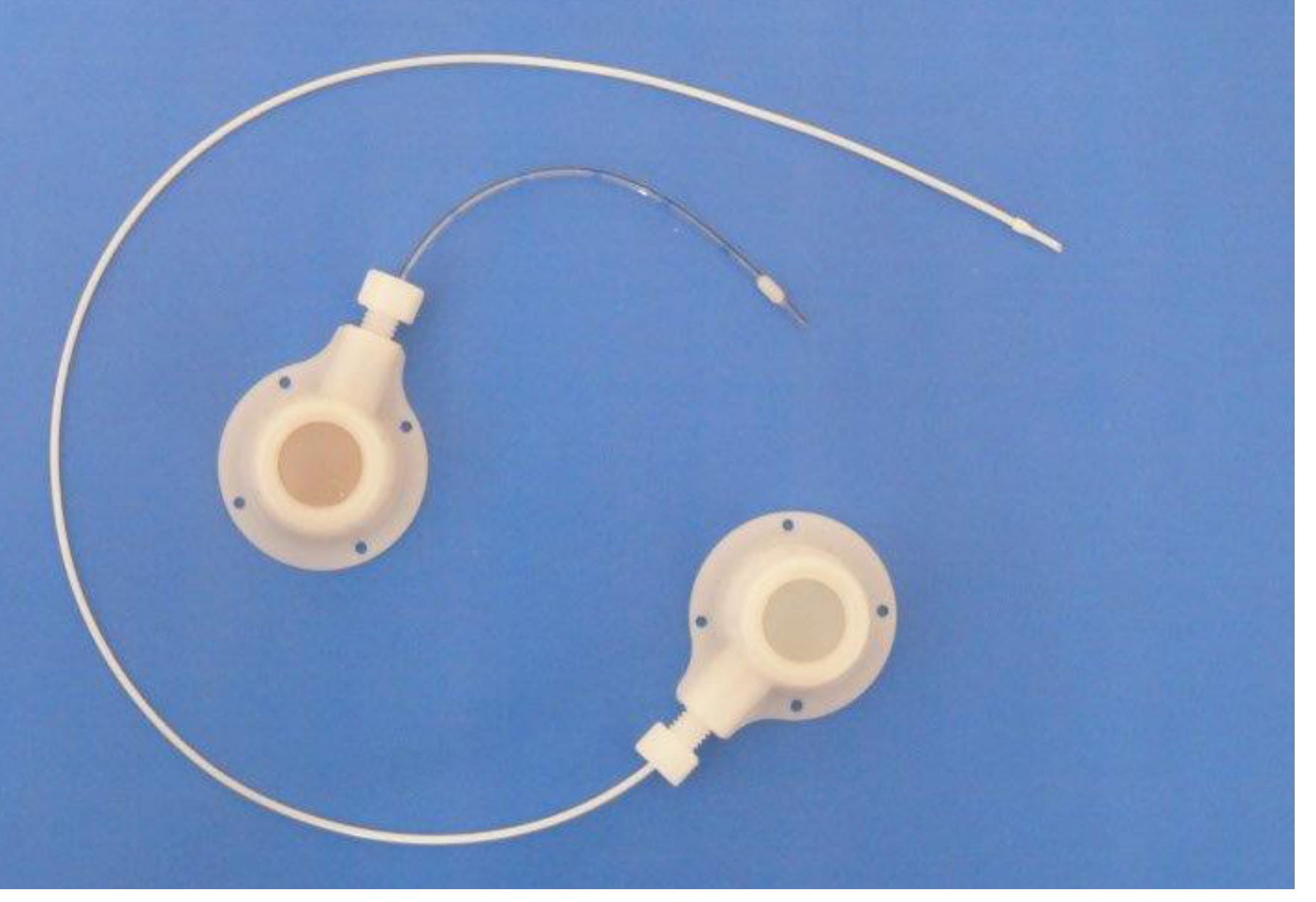

The Jet Port Allround Catheter consists of an ultra thin silicone catheter with an inner diameter of $0.6 \mathrm{~mm}$ and external diameter of $1.05 \mathrm{~mm}$ which is connected with a screw connector to the port chamber. Behind the tip ofthe catheter, there is an olive rim for endto-side fixation in the artery (Fig. 1).

The Implantation is performed in general anesthesia. Through a transverse incision above the clavicular, the common carotid artery is exposed and a 5.0 prolene purse string suture is placed in the adventitial layer of the artery (Fig. 2). The tip of the catheter is inserted through a stab incision and fixed with the prolene suture below and above the olive rim (Fig. 3). The catheter is exited behind the sternocleidomastoideus muscle, connected with the port (Fig. 4) and placed in a subcutaneous pouch below the clavicula. Contrast imaging (Fig. 5) shows the correct position of the implanted catheter.
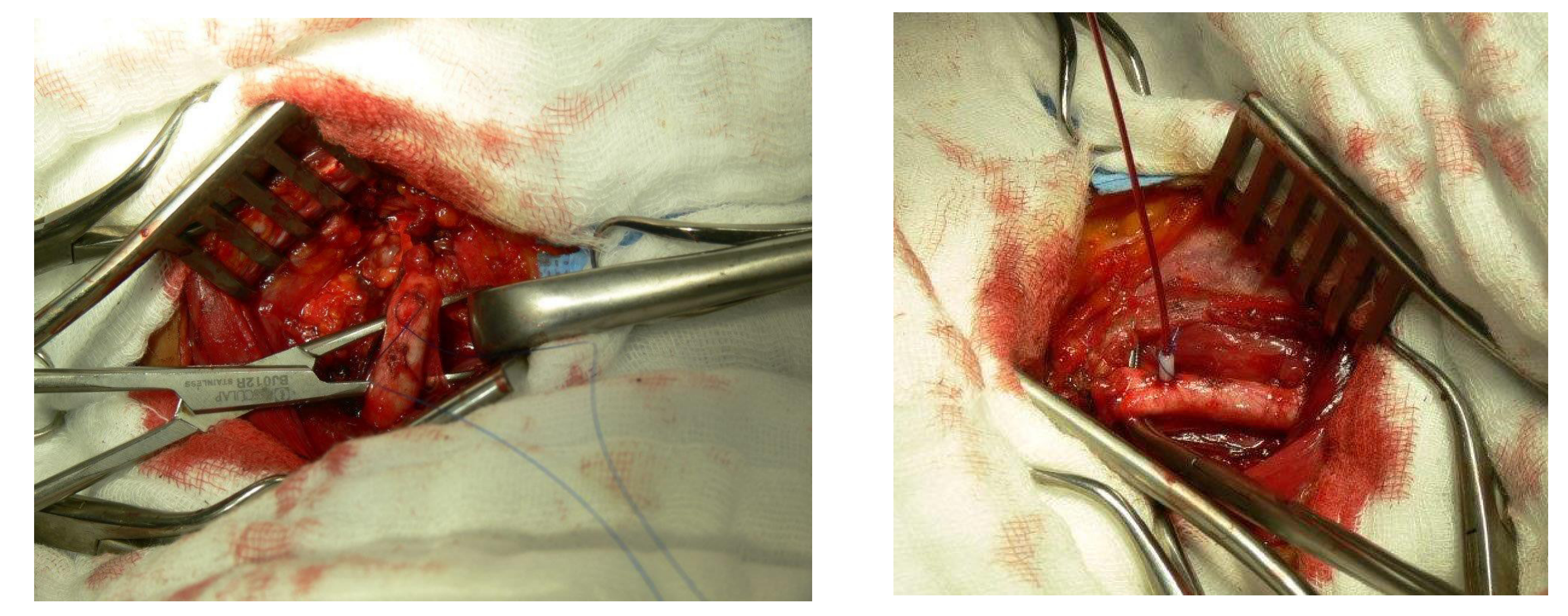
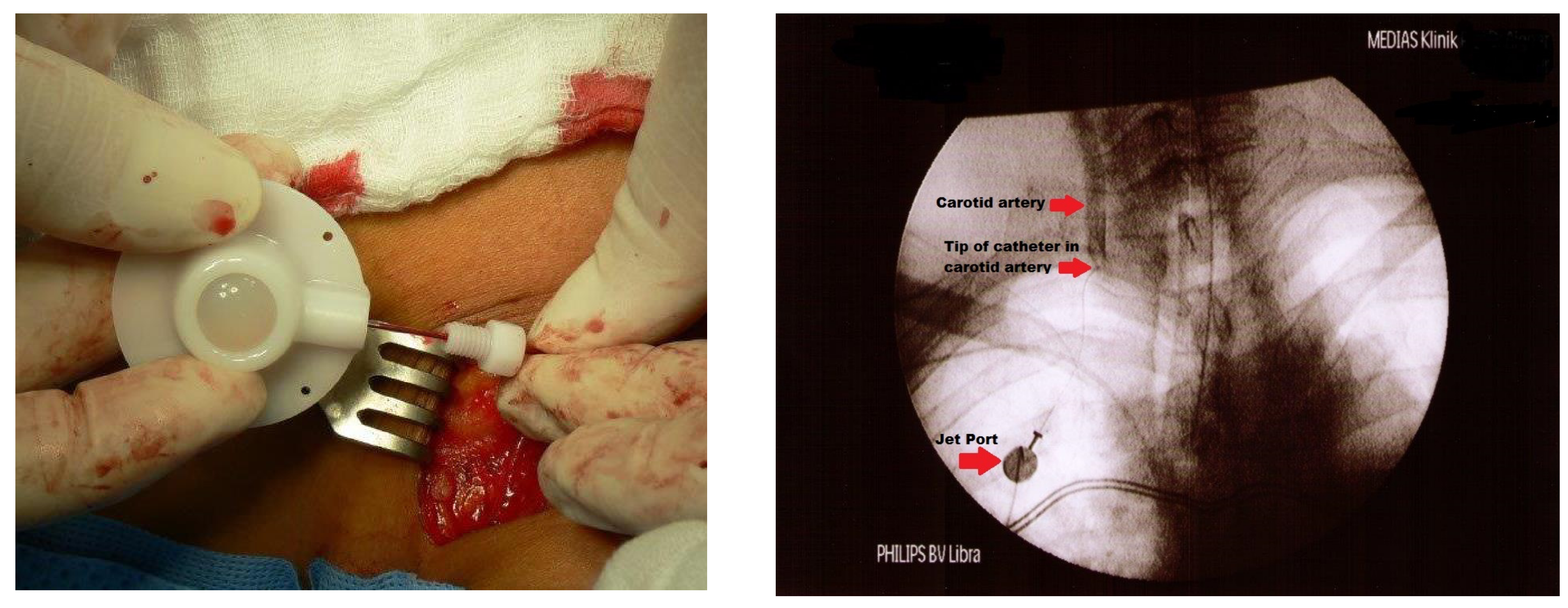
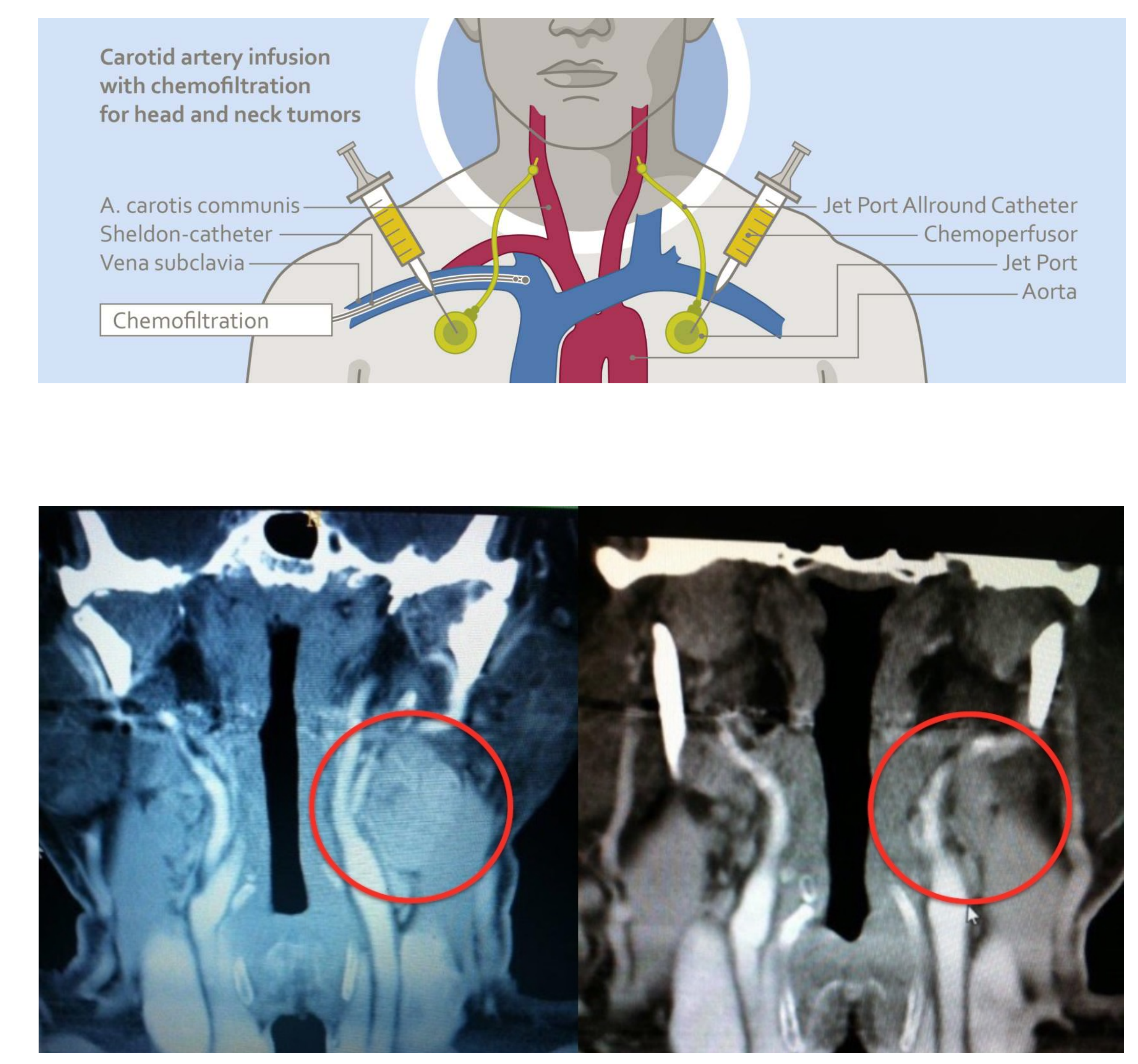

Intra-arterial chemotherapy is performed either in terms 7 - 10 minutes short-term infusions on four consecutive days or as a total dose infusion with simultaneous chemofiltration (Fig. 6) or isolated thoracic perfusion with simultaneous infusion of chemotherapeutics (Cisplatin containing compounds) through the implanted catheters. Jet Port catheters were never flushed between the treatment cycles. For prophylaxis of thrombosis Aspirin 100/day is given for three months.

\section{Results}

Seven non-preirradiated and chemonaive patients with advanced disease in six cases have been disease-free for 16 to 117 months. In most cases, tumor shrinkage is seen within $2-3$ weeks after the first treatment (Fig. 7/8). Patients who had relapsed after prior radiochemotherapy (4/11) showed only poor response due to connective tissue fibrosis from irradiation with reduced blood flow and median survival was 7.5 months.

Haematological toxicity was low, not exceeding WHO grade II, neurological- or ototoxicty, xerostomia or dysphagia never occurred. No patient needed tracheostomy or tube feeding.

Conclusion Intra-arterial infusion generates high regional drug concentrations despite low total dosages, depending on the arterial blood flow and infusion time of the drugs. In combination with chemofiltration, systemic toxicity is kept low. Chemotherapy through implantable Jet Port Allround carotid artery catheters is safe, facilitates intra-arterial chemotherapy as compared with angiographic procedures and shows considerable improvement of locoregional control associated with quality of life.

Literature:

Aigner KR, Selak E, Schlaf R. Isolated Thoracic Perfusion with Carotid Artery Infusion for Advanced and Chemoresistant Tumors of the Parotid Gland and Tonsils. In: Aigner KR, Stephens F0, editors. Induction Chemotherapy - Systemic and Locoregional. Second Edition. Berlin-Heidelberg: Springer-Verlag; 2016: 123-130 Aigner KR, Gailhofer S, Aigner K. Carotid artery infusion via implantable catheters for squamous cell carcinoma of the tonsils. World Journal of Surgical Oncology, 2018. 